\title{
Impact of Chronic Pancreatitis on Pancreatic Resections for Malignancy
}

\author{
Jill K Onesti ${ }^{1,2^{*}}$, G Paul Wright ${ }^{1,2}$, Payal P Attawala ${ }^{2}$, Deepali H Jain ${ }^{1,2}$, Arida Siripong ${ }^{1}$ and Mathew $\mathbf{H}_{\text {Chung }}$ M $^{1,2,3}$ \\ ${ }^{1}$ M.D, GRMEP/MSU General Surgery Residency, Grand Rapids, MI, USA \\ ${ }^{2}$ Michigan State University College of Human Medicine, Grand Rapids, MI, USA \\ ${ }^{3}$ Spectrum Health Medical Group, Grand Rapids, MI, USA
}

Received Date: 23 April 2014, Accepted Date: 5 May 2014, Published Date: 9 May 2014

*Corresponding author: Jill K Onesti, M.D. 221 Michigan St NE, Grand Rapids, MI 49503, USA Tel: 616.391.1691, Fax: 616.391.8611, E- mail: jill.onesti@grmep.com

Copyright: ( 2014 Onesti JK, et al. This is an open-access article distributed under the terms of the Creative Commons Attribution License, which permits unrestricted use, distribution, and reproduction in any medium, provided the original author(s) and source are credited.

\begin{abstract}
Background: Chronic pancreatitis has been shown to have potential benefit in pancreatic resections by reducing postoperative pancreatic fistula. We sought to investigate the impact of chronic pancreatitis on oncologic surgical outcomes.

Materials and Methods: Consecutive partial pancreatectomies performed for malignant disease from 2005-2011 were reviewed. Patients were divided for analysis based on the presence of chronic pancreatitis. The primary outcome measures were need for intraoperative re-excision of margins and final margin status. Secondary outcome measures included pancreatic fistula rate and overall morbidity which were graded in standardized fashion. Significance was assessed for $p<0.05$.

Results: One hundred fifty-four patients met criteria for study, 48 of which had chronic pancreatitis. Demographics, co-morbidities, diagnoses, and surgical technique were equivalent between groups. Though there was a trend towards increased re-excision of margins in the chronic pancreatitis group $(p<0.08)$, there were no significant differences in any surgical outcome measures between groups including final margin status, pancreatic fistula rate, and overall morbidity. Multivariate analysis failed to identify chronic pancreatitis as a predictive factor for any of the chosen outcome variables.
\end{abstract}

Conclusion: Despite potential for difficult dissection due to inflammatory changes in chronic pancreatitis, we found no differences in oncologic outcomes in patients undergoing pancreatectomy.

\section{Introduction}

The effects of pancreatitis on fistula formation after pancreatic resection have been presented in numerous studies [1-6]. Many of these studies have revealed a beneficial component of pancreatitis in providing a firmer parenchyma on which to sew or staple, thereby decreasing the incidence of postoperative fistula. Accordingly, the combination of a small duct and soft gland has been found to be associated with a drastically higher rate of complications relating to the pancreatic duct anastomosis in pancreaticoduodenectomy [4].

Despite the importance of avoiding pancreatic fistula, the importance of efficacy for oncologic resections is paramount to the patient's long-term outcome. Firm texture and inflammation of the pancreas in the face of chronic pancreatitis can confound accurate assessment of gross tumor margins as well as create increased friability in dissecting adjacent tissue planes [5,7]. Little data exist specifically examining the role of pancreatitis on oncologic resections.

Given these considerations, we sought to examine the impact of chronic pancreatitis on a cohort of patients undergoing resection for pancreatic malignancy.

\section{Methods}

The study was designed as a retrospective review of consecutive partial pancreatectomies performed from July 21, 2005 to July 21, 2011. Operations were performed at a university-affiliated teaching hospital by a single surgeon. Patients with benign or pre-malignant (mucinous cystadenoma, main-duct intraductal papillary mucinous neoplasm) disease were excluded.

Subjects were analyzed in groups based on the presence of chronic pancreatitis in the surgical specimen. Chronic pancreatitis was considered present if indicated on final pathology. Clinical history of pancreatitis was also elicited from the medical record. Variables collected included demographics, co-morbid conditions, surgical details, final diagnosis, need for intraoperative margin re-excision, final margin status, and 30-day postoperative morbidity and mortality. Co-morbidities were categorized by the Charlson Co-Morbidity Index (CCI) [8]. Pancreatic fistulas were graded according to the International Study Group on Pancreatic Fistula (ISGPF) classification [9]. Operatively placed drains were not routinely analyzed for amylase levels, leading to a falsely low reporting of grade A fistulas. Therefore, only grade B \& C fistulas were considered. Surgical morbidities were graded by the Clavien-Dindo classification and grade III or higher were included in the analyses concerning overall morbidity [10]. Ductal size was not available for all cases and thus was not used. Small ducts, however, were managed with stents and use of ductal stent is a 
generalized surrogate marker for duct size in this series. The primary outcome measures were need for margin re-excision and final margin status. Secondary outcome measures were postoperative pancreatic fistula and overall morbidity rates.

\section{Ethics}

The study received Institutional Review Board approval prior to data collection, and was performed in accordance with the World Medical Association Declaration of Helsinki - Ethical Principles for Medical Research Involving Human Subjects. Written consent from the patients was waived by the Institutional Review Boards on the grounds of a retrospective review that did not directly benefit or harm the patient other than potential loss of confidentiality. Records were maintained in accordance with privacy standards.

\section{Statistics}

Comparisons between groups were made using chi-squared or Fisher's exact test as indicated for categorical variables and the student's $t$-test for continuous variables. A multivariate logistic regression model was used to account for age, gender, body mass index (BMI), CCI, surgical procedure, method of pancreatic transection, use of ductal stent, and final pathology. Significance was assessed for $\mathrm{p}<0.05$.

\section{Results}

Two hundred fifty nine partial pancreatectomies were performed during the study period. One hundred five patients were excluded for benign or premalignant histology leaving 154 patients for review. The population was distributed equally by gender and had few serious comorbidities (Table 1). The majority of patients underwent pancreaticoduodenectomy and the most common diagnosis was pancreatic adenocarcinoma.

Table I: Patient Demographics $(\mathrm{n}=154)$.

\begin{tabular}{|c|c|c|}
\hline & & $\mathbf{N}(\%)$ \\
\hline \multicolumn{2}{|l|}{ Age (mean $\pm S D)$} & $65.0 \pm 12.3$ \\
\hline \multirow{2}{*}{ Gender } & Female & $71(46.1 \%)$ \\
\hline & Male & $83(53.9 \%)$ \\
\hline \multicolumn{2}{|l|}{ BMI (mean \pm SD) } & $27.6 \pm 6.0$ \\
\hline \multirow{4}{*}{ Charlson Co-morbidity Index } & 2 & $85(55.2 \%)$ \\
\hline & 3 & $51(33.1 \%)$ \\
\hline & 4 & $15(9.7 \%)$ \\
\hline & $\geq 5$ & $3(1.9 \%)$ \\
\hline \multirow{2}{*}{ Chronic pancreatitis } & Yes & $48(31.2 \%)$ \\
\hline & No & $106(68.8 \%)$ \\
\hline \multirow{2}{*}{ Surgery } & Pancreaticoduodenectomy & $127(82.5 \%)$ \\
\hline & Distal Pancreatectomy & $27(17.5 \%)$ \\
\hline \multirow{2}{*}{ Ductal stent used } & Yes & $41(26.6 \%)$ \\
\hline & No & $113(73.4 \%)$ \\
\hline \multirow{4}{*}{ Final pathology } & Pancreatic adenocarcinoma & $116(75.3 \%)$ \\
\hline & Peri-ampullary adenocarcinoma & $10(6.5 \%)$ \\
\hline & Cholangiocarcinoma & $3(1.9 \%)$ \\
\hline & Pancreatic neuroendocrine tumor & $25(16.2 \%)$ \\
\hline
\end{tabular}

Forty-eight patients had evidence of chronic pancreatitis on final pathologic examination. In addition, 13 of these patients $(8.4 \%)$ had a clinical history of chronic pancreatitis. Comparison between groups yielded no significant differences in presentation or treatment variables (Table 2). 
Citation: Onesti JK, Wright GP, Attawala PP, Jain DH, iripong A, et al. Impact of Chronic Pancreatitis on Pancreatic Resections for Malignancy. Journal of Surgery [Jurnalul de Chirurgie] 2014; 10(1): 49-53. doi: 10.7438/1584-9341-10-1-9

Page 51

Table II: Pancreatitis Groups.

\begin{tabular}{|l|l|l|l|}
\hline & Pancreatitis $^{*}$ & No Pancreatitis* & p value \\
\hline \hline Age (mean \pm SD) & $(\mathbf{n = 4 8 )}$ & $\mathbf{( n = 1 0 6 )}$ & \\
\hline Gender (Male) & $66.5 \pm 10.2$ & $64.3 \pm 13.2$ & 0.32 \\
\hline BMI & $26(54.2 \%)$ & $57(53.8 \%)$ & 0.96 \\
\hline CCI & $27.0 \pm 5.6$ & $27.8 \pm 6.2$ & 0.45 \\
\hline Surgery (Pancreaticoduodenectomy) & $2.7 \pm 0.7$ & $2.6 \pm 0.9$ & 0.62 \\
\hline Stent used & $41(85.4 \%)$ & $86(81.1 \%)$ & 0.52 \\
\hline Pathology (Pancreatic adenocarcinoma) & $12(25.0 \%)$ & $29(27.4 \%)$ & 0.76 \\
\hline
\end{tabular}

Surgical outcomes are listed in Table 3. Though the percentage of patients requiring intraoperative re-excision for margins and having final positive margins was higher in the pancreatitis group, these were not statistically significant. The pancreatic fistula rate was $6.5 \%$ for the entire cohort and there were no differences between groups. Overall morbidity and mortality rates were $23.4 \%$ and $1.3 \%$, respectively, with equal distribution amongst the two groups.

Table III: Pancreatectomy outcomes based on presence of pancreatitis; ${ }^{\star}$ mean \pm SD; \# $n=37$ for pancreatitis and $n=79$ for no pancreatitis; @ $\mathrm{n}=105$ for no pancreatitis.

\begin{tabular}{|c|c|c|c|}
\hline & Pancreatitis & No Pancreatitis & p value \\
\hline OR duration* & $295 \pm 78$ & $310 \pm 89$ & 0.30 \\
\hline Estimated blood loss* & $583 \pm 373$ & $536 \pm 356$ & 0.46 \\
\hline Intraoperative re-excision for margins & $8(16.7 \%)$ & $7(6.6 \%)$ & 0.08 \\
\hline Final margins positive & $20(41.7 \%)$ & $32(30.2 \%)$ & 0.16 \\
\hline Days to tolerating $\operatorname{diet}^{\star} \#$ & $8.0 \pm 3.8^{\wedge}$ & $8.2 \pm 4.3 \&$ & 0.85 \\
\hline Duration of JP drainage@ & $7.9 \pm 4.4$ & $7.4 \pm 4.5$ & 0.50 \\
\hline SSI & $1(2.1 \%)$ & $2(1.9 \%)$ & $>0.999$ \\
\hline Thromboembolic event & $5(10.4 \%)$ & $6(5.7 \%)$ & 0.32 \\
\hline Pancreatic fistula & $3(6.3 \%)$ & $7(6.6 \%)$ & $>0.999$ \\
\hline Re-exploration & $1(2.1 \%)$ & $3(2.8 \%)$ & $>0.999$ \\
\hline ICU duration* & $2.1 \pm 1.9$ & $2.4 \pm 3.4$ & 0.57 \\
\hline ICU readmission & $2(4.2 \%)$ & $4(3.8 \%)$ & $>0.999$ \\
\hline Hospital LOS* & $14.2 \pm 7.9$ & $13.7 \pm 8.1$ & 0.72 \\
\hline Disposition home & $89(84.0 \%)$ & $34(70.8 \%)$ & 0.16 \\
\hline Morbidity & $13(27.1 \%)$ & $23(21.7 \%)$ & 0.47 \\
\hline Mortality & $1(2.1 \%)$ & $1(0.9 \%)$ & 0.53 \\
\hline
\end{tabular}

Multivariate analysis revealed that the presence of chronic pancreatitis was not associated with worse outcomes for any of the chosen measures (Table 4). For intraoperative re-excision of margins, however, this was approaching statistical significance. Patients with pancreatic adenocarcinoma were far more likely to have positive final margins than those with peri-ampullary adenocarcinoma, cholangiocarcinoma, or neuroendocrine tumors (OR 6.4, 95\% CI 2.1-19.7).
Table IV: Multivariate Analysis - Effect of Chronic Pancreatitis.

\begin{tabular}{|l|c|}
\hline Outcome Variable & OR $(95 \% \mathrm{Cl})$ \\
\hline Pancreatic Fistula & NS \\
\hline Morbidity & NS \\
\hline
\end{tabular}




\begin{tabular}{|l|c|}
\hline Intraoperative Re-excision for Margins & $2.8(0.96-8.3)$ \\
\hline Final Margins Positive & NS \\
\hline
\end{tabular}

\section{Discussion}

Chronic pancreatitis has been shown to have a protective effect on the development of postoperative pancreatic fistula [4,5]. Despite this benefit, chronic inflammation may result in difficulty assessing gross margins in patients with malignant pancreatic disease and lead to a more tedious dissection [7]. In this study we analyzed 154 patients who underwent partial pancreatectomy for malignancy and though nearly one-third of patients had chronic pancreatitis, there were no differences in oncologic or standard surgical outcomes associated with this finding.

The primary goal in patients with malignant disease is to achieve an $\mathrm{R} 0$ resection to improve survival. This can be complicated in patients with inflammation surrounding the pancreas either from chronic pancreatitis or desmoplastic reaction. Few studies to date have specifically examined the role of chronic pancreatitis in performing oncologic resections. In our study we chose need for intraoperative reexcision of margins and positive final margins as the primary outcome measures. There were no differences in outcome measures between groups based on the presence of chronic pancreatitis, though there was a trend towards increased need for intraoperative re-excision of margins. This is likely related to difficulty in palpating or visualizing normal tissue in the face of inflammatory change and firmer pancreatic parenchyma. Despite this trend there was no difference in final margin status between groups based on the presence of pancreatitis. The only predictive factor for positive margins on final pathology was a diagnosis of pancreatic adenocarcinoma as compared to the other malignancies evaluated. Elevated R1 resection rates have been consistently reported in pancreatic adenocarcinoma and is likely indicative of early metastasis as demonstrated in animal models [11].

Reports on the rate of postoperative pancreatic fistula have varied greatly. The ISGPF has provided a concise, reproducible definition of pancreatic fistulas, allowing for standardization across studies [9]. The role of pancreatitis on fistula formation has been investigated in both pancreaticoduodenectomy and distal pancreatectomy with varying results. Risk factors for development of postoperative pancreatic fistula include obesity, increased operative blood loss, and sutured closure without main duct ligation, amongst others [6]. In studies demonstrating decreased fistula rates it has been proposed that a firmer parenchyma is protective against fistula formation. The results presented here demonstrate a low pancreatic fistula rate of $6.5 \%$. Additionally, the study was largely comprised of patients undergoing pancreaticoduodenectomy which has been demonstrated to have a lower fistula rate than distal pancreatectomy [6]. With a low fistula rate, there were no differences in postoperative pancreatic fistula observed between patient groups based on the presence of pancreatitis in our study.

In addition to postoperative pancreatic fistula, the effect of chronic pancreatitis on other surgical morbidities is unclear. We defined postoperative morbidities in a consistent fashion using the ClavienDindo classification and found there was no difference in morbidity rates between groups. Additionally, mortality was equal between groups as well. Despite the operative challenges posed by increased chronic inflammation of the pancreas, it appears this has no impact on short-term surgical outcomes.

This study is limited in its analysis by the retrospective design, however, utilizing standardized definitions for postoperative morbidities allowed for reduction of observation bias. Ductal size was not specifically identified for each patient and therefore is not reported. Ductal stents were, in general, used solely in the case of small ducts and this variable serves as a surrogate marker of duct size though is not exact. Long term survival was not examined for this study, though it is unlikely that a significant impact would be seen as there were no differences in margin positivity or short-term outcomes.

\section{Conclusions}

In conclusion, 154 patients with pancreatic cancer were investigated to determine the impact of chronic pancreatitis on oncologic outcomes following partial pancreatectomy. There were no differences identified in either need for intraoperative re-excision for positive margins or final margin status. Moreover, postoperative morbidity and mortality rates were equivalent between groups. These data suggest that despite technical challenges involved in performing pancreatic surgery in patients with chronic pancreatitis, successful outcomes can be obtained without sacrificing oncologic efficacy.

\section{Acknowledgments}

Alan T. Davis, Ph.D., and Tracy J. Frieswyk, M.A. for statistical analysis and manuscript review.

\section{References}

1. Subhedar PD, Patel SH, Kneuertz PJ, Maithel SK, Staley CA, et al. (2011) Risk factors for pancreatic fistula after stapled gland transection. Am Surg 77: 965-970.

2. Braga M, Capretti G, Pecorelli N, Balzano G, Doglioni C, et al. (2011) A prognostic score to predict major complications after pancreaticoduodenectomy. Ann Surg 254: 702-707.

3. Räty S, Sand J, Lantto E, Nordback I (2006) Postoperative acute pancreatitis as a major determinant of postoperative delayed gastric emptying after pancreaticoduodenectomy. J Gastrointest Surg 10: 1131-1139.

4. Ansorge C, Strömmer L, Andrén-Sandber A, Lundell L, Herrington MK, et al. (2012) Structured intraoperative assessment of pancreatic gland characteristics in predicting complications after pancreaticoduodenectomy. Br J Surg 99: 1076-1082.

5. Chu CK, Sarmiento JM, Park J, Staley CA, Galloway JR, et al. (2010) Differences in presentation and perioperative outcome after pancreaticoduodenectomy for cancer and benign pancreatitis. Am Surg 76: 606-613.

6. Belyaev O, Munding J, Herzog T, Suelberg D, Tannapfel A, et al. (2011) Histomorphological features of the pancreatic remnant as independent risk factors for postoperative pancreatic fistula: a matched-pairs analysis. Pancreatology 11: 516-524.

7. Garcea G, Metcalfe MS, Berry DP, Robertson GS, Lloyd DM, et al. (2012) Is intraoperative confirmation of malignancy during pancreaticoduodenectomy mandatory? J Gastrointest Surg 16: 370-375.

8. Charlson ME, Pompei P, Ales KL, MacKenzie CR (1987) A new method of classifying prognostic comorbidity in longitudinal studies: development and validation. J Chronic Dis 40: 373-383.

9. Bassi C, Dervenis C, Butturini G, Fingerhut A, Yeo C, et al. (2005) Postoperative pancreatic fistula: An international study (ISGPF) definition. Dindo D, Demartines N, Clavien PA. (2004) Classification of 
Citation: Onesti JK, Wright GP, Attawala PP, Jain DH, iripong A, et al. Impact of Chronic Pancreatitis on Pancreatic Resections

for Malignancy. Journal of Surgery [Jurnalul de Chirurgie] 2014; 10(1): 49-53. doi: 10.7438/1584-9341-10-1-9

Page 53

surgical complications: A new proposal with evaluation in a cohort of 6336 patients and results of a survey. Ann Surg 240: 205-13.

10. Rhim AD, Mirek ET, Aiello NM, Maitra A, Bailey JM, et al. (2012) EMT and dissemination precede pancreatic tumor formation. Cell 148 349-361.
11. Goh BK, Tan YM, Chung YF, Cheow PC, Ong HS, et al. (2008) Critical appraisal of 232 consecutive distal pancreatectomies with emphasis on risk factors, outcome, and management of the postoperative pancreatic fistula: a 21-year experience at a single institution. Arch Surg 143: 956-965. 